\title{
EVALUATION OF THE RADIANT COOLING CEILING PANELS WITH A REVERSIBLE HEAT PUMP
}

\section{MIROSLAV RIMAR, MARCEL FEDAK, ANDRII KULIKOV, OLHA KULIKOVA}

Technical University of Kosice, Faculty of Manufacturing, Technologies with a seat in Presov, Department of Process Technique, Presov, Slovak Republic

DOI: 10.17973/MMSJ.2021_12_2021120

e-mail : miroslav.rimar@tuke.sk

Thermal comfort is one of the basic prerequisites for appropriate operating of the building. Ensuring thermal comfort in the summer means creating suitable thermal conditions in the interior. The present article evaluates the operation of radiant ceiling cooling, which is a suitable alternative for conventional cooling systems. Experimental cooling systems using a reversible heat pump as a source of chilled water were analyzed. The presented results indicate the ability of the system to ensure the required interior temperature under suitable climatic conditions using appropriate time management and sufficient accumulation. The required temperature is $24.51{ }^{\circ} \mathrm{C}$ and the deviation does not exceed $\pm 0.5 \mathrm{~K}$.

KEYWORDS

radiant cooling, ceiling cooling, reversible heat pump, energy storage

\section{INTRODUCTION}

Ensuring thermal comfort in the building is one of the important aspects in the design of a suitable air conditioning system. Thermal comfort is a state when people which are using the given spaces of the building feels comfortable in the building, without the perception of heat load. Thermal wellbeing is a highly subjective state depending on the ambient temperature, humidity, air velocity, but also on the metabolism of a person, the actual clothing of a person, so it depends on the feelings and physiology of a particular person [Micallef 2016, Kalliomaki 2016, Driss 2016]. According to ANSI / ASHRAE Standard 55-2010 (Thermal Environmental Conditions for Human Occupancy) thermal comfort is a condition of mind that expresses satisfaction with the thermal environment. Because there are large variations, both physiologically and psychologically, from person to person, it is difficult to satisfy everyone in a space. Further as stated by ANSI / ASHRAE Standard 55-2010 [ANSI/ASHRAE Standard 55-2010] there are six primary factors that must be addressed when defining conditions for thermal comfort: (1) Metabolic rate; (2) Clothing insulation; (3) Air temperature; (4) Radiant temperature; (5) Air speed; (6) Humidity.

In conventional systems, the heat load is removed by flowing air of the desired temperature. These systems are characterized by significant values of the air velocity in the room [Jeong 2003], which may not meet the subjective needs as well as the requirements defined by the norms. A suitable alternative is to use so-called ceiling cooling. Passive ceiling cooling systems are one of the promising technologies among other cooling systems in buildings [Xie 2016]. The principle of ceiling cooling is a cooling the ceiling surface to a certain desired temperature. In the case of comparison of cooled panels with air systems, the application of radiant cooling panels changes the dynamics of heat transfer in a annalized space. Heat is removed from the zone by radiation in comparison with conventional air systems where only the convection heat transfer system is used [Causone 2009]. According to [Olesen 2000], the radiant heat transfer coefficient expresses the radiant heat representing the exchange between a particular surface and all other surfaces in the room. Depending on the parameters such are Stefan Boltzmann constant and emissivity, it can also be considered as a constants for any type of radiant cooling system. The clooling surface is characterized by the ability to remove radiant heat, the source of which is any external source or internal active sources, as well as from internal surfaces within the array of panels [Imanari 1999]. The cooling of the interior space when using cooled ceilings is mostly carried out by radiation with a share of up to $60 \%$. According to [Corny 2009, Tian 2012], the exchange of energy by radiation results in a decrease in the accumulation of thermal energy in the mass of the building.

As stated [Chiang 2012], radiant cooling systems represent an energy efficient approach in ensuring suitable conditions in buildings. Due to the large heat exchange area, these cooling systems operate at a water temperature close to the indoor temperature and at the same time increase the annual efficiency of heat pumps or systems using renewable energy sources [Diaz 2010].

The water system of a cooled ceiling consumes significantly less energy for the production of cold than a system using air as a medium [Su 2019]. This is because the temperature of the cooling water in the capillary mat tubes may be higher than the temperature of the cooling air

Cooling systems operate at a water temperature close to the indoor temperature. However, this fact limits the amount of energy dissipated per unit area due to the low value of the thermal gradient [Vahovsky 2019]. This is limited by the effect of the dew point. When operating the system, it is not possible to use low temperatures of the heat transfer medium due to exceeding the dew point values [Corny 2013]. Another fact is the physical properties of the used heat transfer medium water. Water is used most often due to the high value of specific heat capacity. The use of antifreeze mixtures in tanks does not bring the desired effect precisely because of the decrease in the heat capacity of the working substance [Nahornyi 2018, Rimar 2018, Lenhard 2019].

\section{RADIANT COOLING SYSTEM AND A REVERSIBLE HEAT PUMP}

The aim of the experiment was to monitor the course of quantities in the production of cold within the operation of the cooling system of the building using radiant cooling ceilings. The experimental measurements were performed on a cooling system operated according to the diagram (Fig. 1) of a part of a multivalent system [Murcinkova 2013]. The experimentally developed functional structure consists of a two-compressor reversible air-to-water heat pump WBAN 162. The total cooling capacity of the heat pump is $22.78 \mathrm{~kW}$. The experimental system also consists of a pump group, safety devices, storage tank, three-way diverter valve with drive. During the measurements, the pump was operated in $50 \%$ power mode, ie using one compressor. The outlet temperature of the working medium from the heat pump is in the range of $4.5^{\circ} \mathrm{C}$ to $10{ }^{\circ} \mathrm{C}$. The working substance is then accumulated in the cooling water tank. Subsequently, the thermal energy of the cooling 
system is taken from the chilled water tank with a volume of $800 \mathrm{I}$ by a circulating pump. Cooling in the rooms is realized by cooling radiant ceilings located in the individual rooms of the building. The heat transfer medium is treated demineralized water.

The process level of control as well as the provision of recording of read data from individual measuring nodes is provided by the software system Desico Insight designed on the basis of Siemens Desigo Insight.
The experiment was carried out in the laboratories of the Department of Process Technique in a room $6.7 \mathrm{~m} \times 2.8 \mathrm{~m} \times$ $3.0 \mathrm{~m}$ using ceiling cooling. Contact with the exterior is $1 \mathrm{x}$ perimeter wall and ceiling, the building opening to the exterior is a seven-chamber plastic window with double glazing. Contact with the interior is represented by the floor, $3 x$ inner wall and a building opening into the interior is represented by a door.

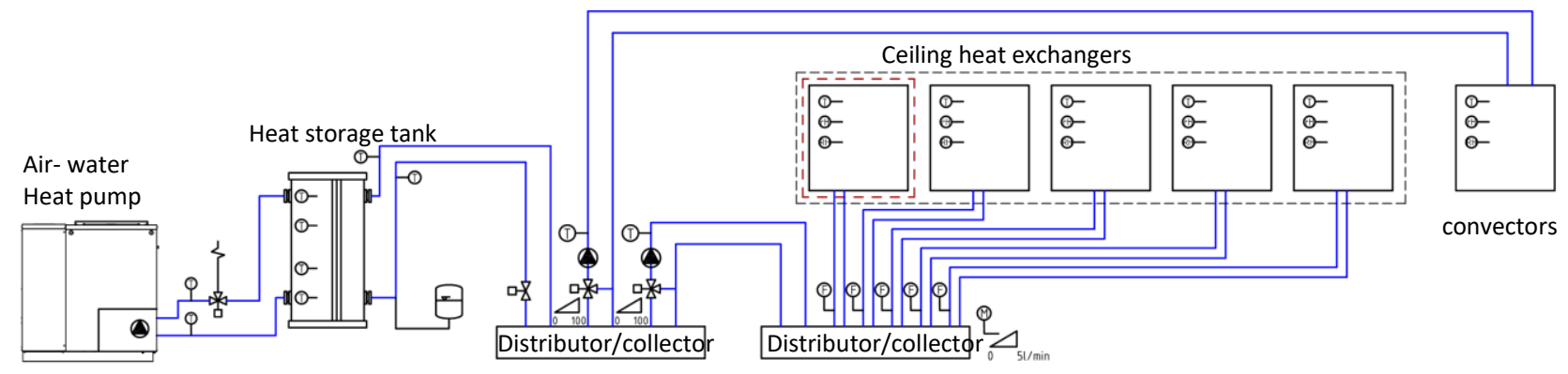

Figure 1. The applied scheme of the system in multivalent laboratory

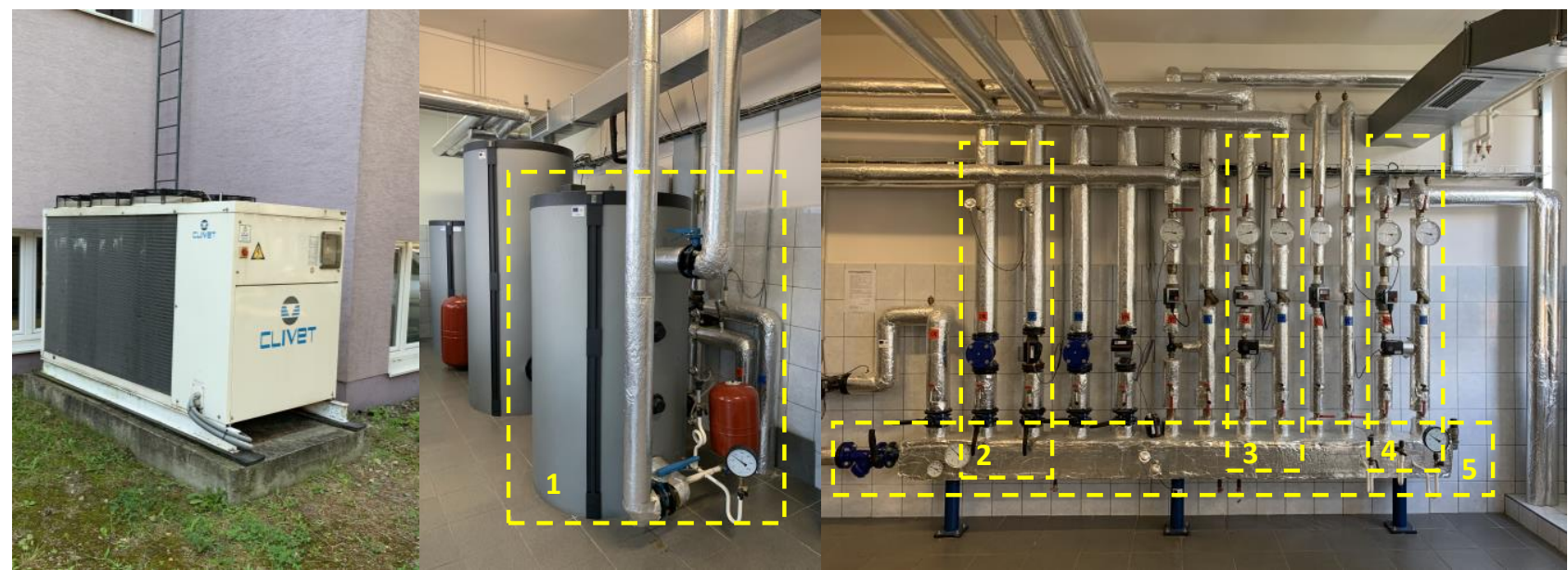

Figure 2. Heat pump operating in cooling mode (left) and laboratory with experiment equipment (right); (1) - water heat storage tank, (2) - heat pump circuit, (3) - ceiling heat exchanger register circuit, (4) - convector system circuit (5) - distributor/collector

\section{RESULTS}

The measurements were performed in three measuring cycles (Fig. 3), while at the start of a new cycle the system was discharged so as not to distort the obtained results. An overview of the evaluated quantities as well as their course is comprehensively shown in Fig. 3. Subsequently, the individual days were compared at Fig. 4. To ensure thermal comfort, the required interior temperature was set to $24.5{ }^{\circ} \mathrm{C}$. The measurement results indicate that this value was reached at the required interior temperature. The analysis of the data points to the fact that the temperature values measured indoors for 24 hours oscillated around the required value in the range from $27{ }^{\circ} \mathrm{C}$ during the time of operation of the cooling system, ie at night, respectively. $28{ }^{\circ} \mathrm{C}$ over the weekend. The operating cycle of the heat pump is set for Monday to Friday with a start time at 6:30 am. and an end of operation time at 2:00 p.m. The circulation pump of the ceiling panel system is activated at 5:00 am. due to the use of residual stored energy from the previous duty cycle. At the same time, the circulation will equalize the temperature in the registers in the individual rooms of the building. The circulation pump is then deactivated at 17:30. The time difference between switching off the heat pump and the circulation pump is 3.5 hours. At this time, the system uses the storage tank (Fig. 2 point (1)). The result is an optimization of the operation of the reversible heat pump, which generates cooled water over time with lower outdoor temperatures. At the maximum outdoor temperature, the heat pump is already deactivated, but the system still ensures sufficient removal of heat in the room. As can be seen from FIG. 4 after activating the system at 5:00 am. there is a gradual decrease in temperature in the whole system. The system reaches the required room temperature at approx. 7:00 am. Subsequently, the room temperature setpoint is maintained at the setpoint, even in the event of a significant change in outdoor temperature.

The relative humidity in the room ranges from $50 \%$ to $58.5 \%$. The cyclical process of charging the storage tank causes the heat pump to run. The water temperature in the tank is maintained by the system at a level of $10.5^{\circ} \mathrm{C}$ to $4.5^{\circ} \mathrm{C}$, which is in accordance with the outlet temperature of the heat pump. This cycling is due to the pump running higher than the current energy consumption. The inlet temperature at the cooling panel system is set on $15{ }^{\circ} \mathrm{C}$ based on the dew point, with an automatic correction when the humidity limit is reached. The maintenance of the maximum dew value is monitored by means of installed dew sensors in the system ceiling. 


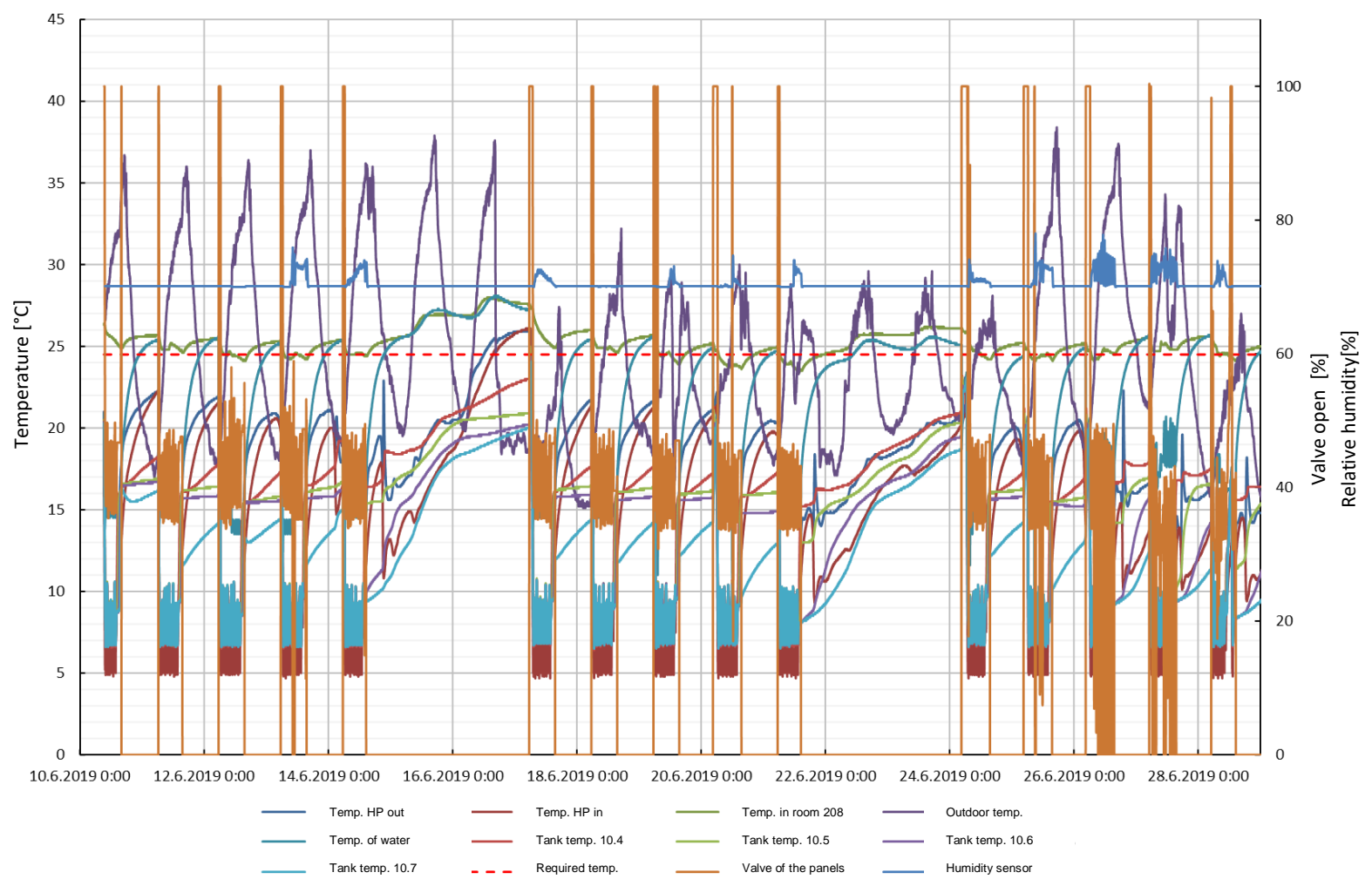

Figure 3. Evaluated parameters monitored during cooling - cumulative display

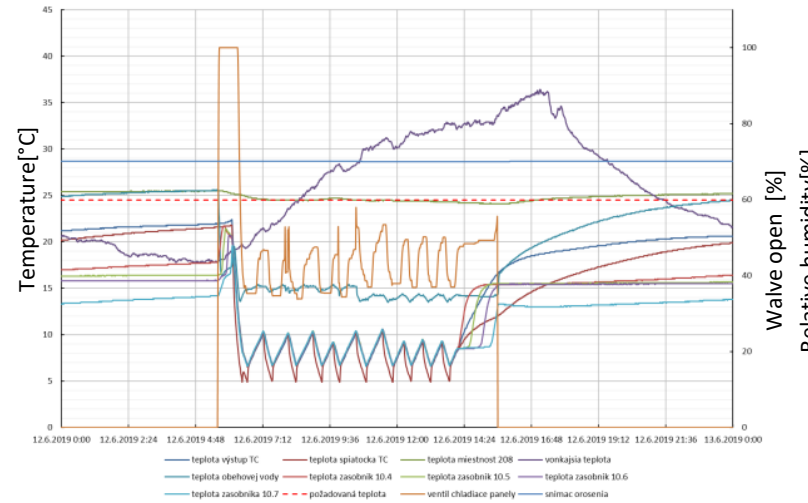

a)

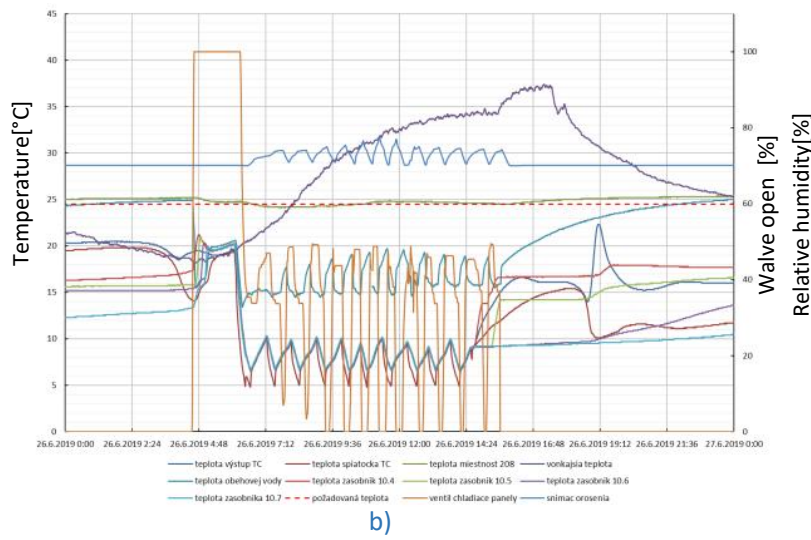

Figure 4. Evaluated parameters monitored during cooling (12.6.2019 and 26.6.2019)

In Fig. 4 b) are shown the dew values of $70 \%$ and subsequent interventions of the control system by means of mixing threeway valves. In this case, when the humidity increases, the control valves close completely. To ensure sufficient cooling potential, the operating temperature range for the cooling system is set from $14{ }^{\circ} \mathrm{C}$ to $16^{\circ} \mathrm{C}$.
When the temperature of the cooling water circulating in the system is below $14{ }^{\circ} \mathrm{C}$, the dew point value is quickly reached as a consequent problem with condensation in the ceiling panel which are in contakt with heat exchanger pipes. At temperatures above $16{ }^{\circ} \mathrm{C}$, the efficiency of the system gradually decreases, where it can no longer sufficiently cover the heat load in the rooms.

As part of the subsequent analysis of the system, measurements were performed using a thermal camera. Using sequential scanning, a thermovision analysis of the entire surface of the ceiling in the room was created (Fig. 5).

The average temperature over the entire area of the analyzed ceiling is $21.7{ }^{\circ} \mathrm{C}$. The temperature of $23.5^{\circ} \mathrm{C}$ is reached by parts of the ceiling without contact with the exchanger. Temperatures of 25 to $28{ }^{\circ} \mathrm{C}$ are measured on the surface of the luminaire. The lowest temperature of the ceiling surface is $17.3{ }^{\circ} \mathrm{C}$ in the areas with an contact with the heat exchanger register. The average temperature of the ceiling structure at the point of contact with the register is about $18.5^{\circ} \mathrm{C}$. The temperature difference between the circulating water in the ceiling cooling system and the surface of the ceiling structure in contact with the register is $4{ }^{\circ} \mathrm{C}$. This difference is due to the thermal resistance of the used gypsum boards.

The thermal profile of the ceiling structure is shown in Figure 6, which shows the temperature profiles in the tropical structure in 20 sections of the ceiling profile.

In Fig. 7 is shown the percentage rating of the temperature distribution. The results show that the ceiling reaches a temperature of up to $22{ }^{\circ} \mathrm{C}$ on about $69 \%$ of the ceiling area, $22 \%$ presents an area with a temperature of $22.1{ }^{\circ} \mathrm{C}$ to $25^{\circ} \mathrm{C}$, $9 \%$ of the ceiling area reaches a temperature of $25.1{ }^{\circ} \mathrm{C}$ to $28^{\circ} \mathrm{C}$. The results show that the temperature is lower than the required room temperature on about $94 \%$ of the surface. In terms of the results achieved, it can be stated that the system of cooled radiant ceilings achieves the desired results, even at times of high outdoor temperatures. At the same time, in 
conjunction with a suitable control system, it is possible to ensure operation without condensation problems.

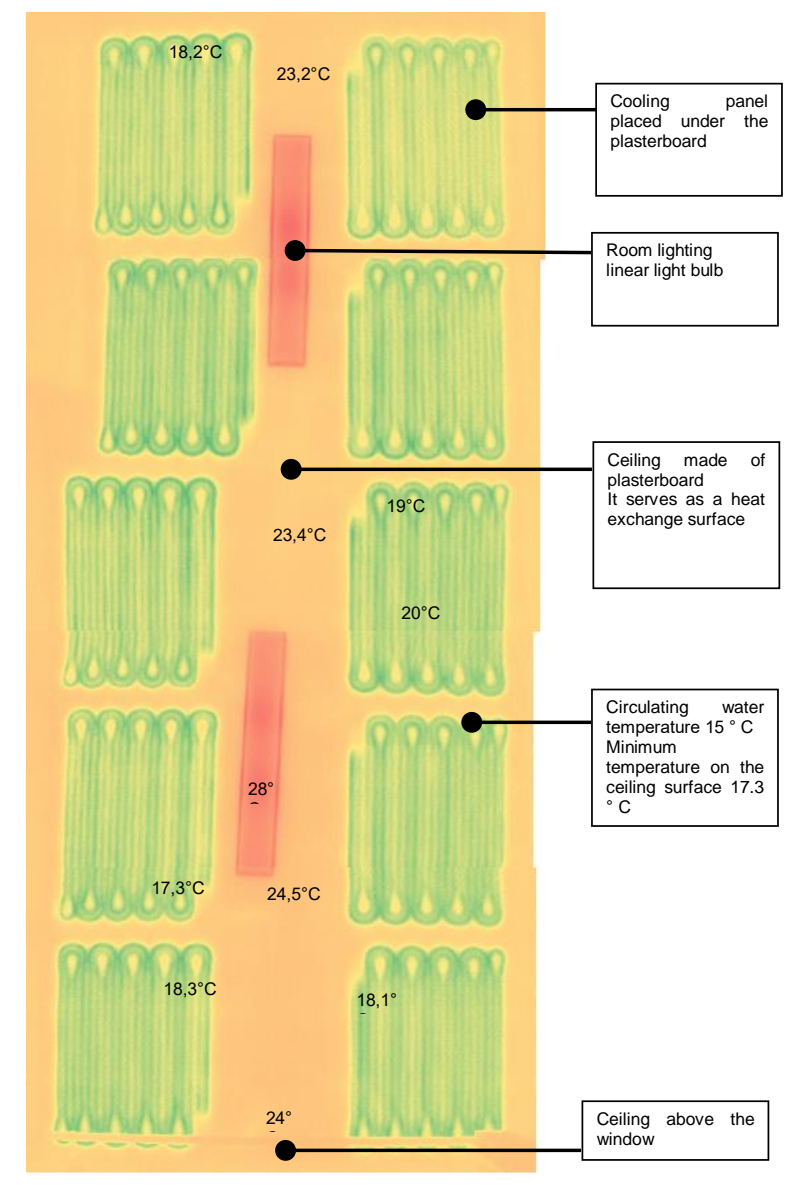

Figure 5. Thermal image - cooled ceiling during the experiment

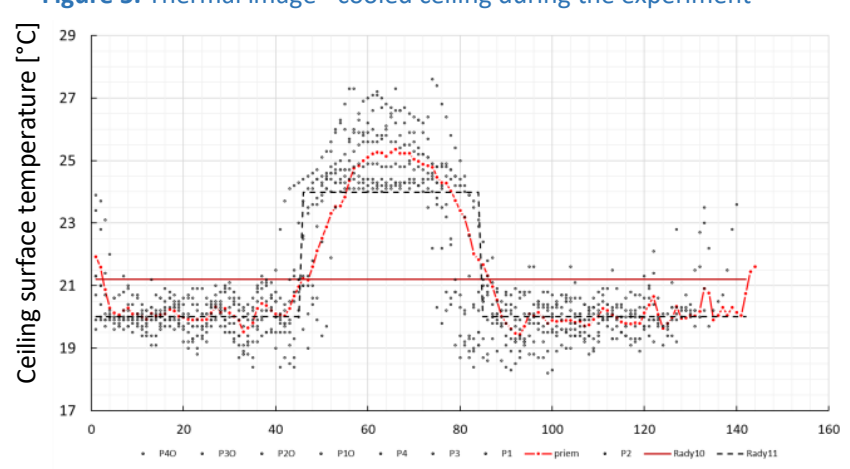

Figure 6. Cross section of the ceiling forming the thermal profile presents 20 cross sections

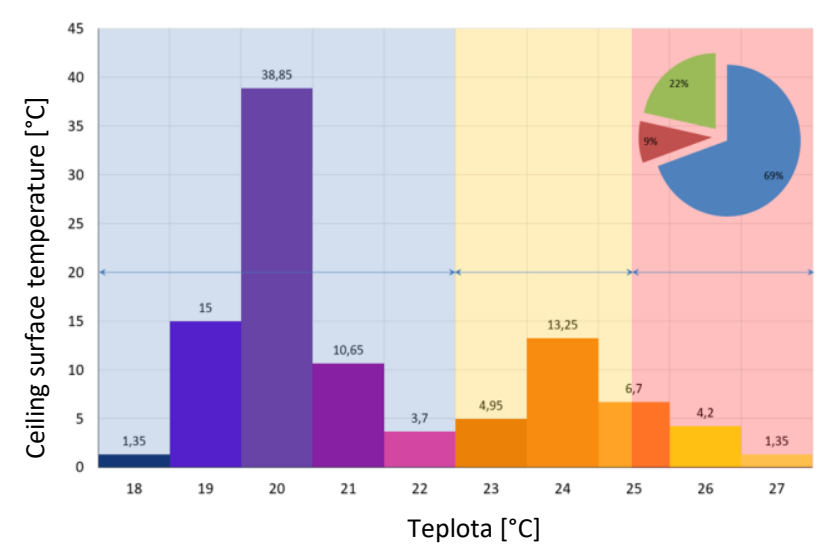

Figure 7. Percentage temperature distribution on the ceiling surface

\section{CONCLUSIONS}

Ensuring thermal comfort is currently one of the important tasks in the operation of buildings. Thermal comfort in the summer currently represents the need to remove the heat load in the interiors. The thermal load is on the one hand individual indoor sources such as the operation of computer technology or other sources producing heat, on the other hand it is the person himself, also, the last but not least it is the heat gains from the exterior. At present, it is possible to observe a gradual increase in average summer temperatures, the result of which is an increase in the requirements to ensure the required standard. One of the possibilities is the use of cooling systems based on radiant cooling ceilings. The results presented in this paper indicate the suitability of applying a cooling ceiling using a reversible heat pump. Based on the defined requirements in the form of an interior temperature of $24.5^{\circ} \mathrm{C}$, the system can remove the heat load in a suitable way using a water-based heat transfer medium with a temperature of $15{ }^{\circ} \mathrm{C}$. The evaluated system is optimized so that the temperature of the working medium reaches the optimal temperature in relation to the dew point. When the humidity limit is reached, an automatic correction takes place. To ensure sufficient cooling potential, the operating temperature range for the cooling system is set from $14{ }^{\circ} \mathrm{C}$ to $16^{\circ} \mathrm{C}$. At temperatures above $16{ }^{\circ} \mathrm{C}$, the efficiency of the cooling system decreases, which in turn cannot sufficiently cover the heat load in the rooms. Further analysis showed the ability of the system to use up to $94 \%$ of the ceiling area for cooling, $55.5 \%$ of the ceiling surface reaches a temperature below $21{ }^{\circ} \mathrm{C}$, which represents a sufficient temperature difference compared to objects in interiors, including people.

\section{ACKNOWLEDGMENTS}

This work was supported by the Slovak Research and Development Agency under the contract No. APVV-16-0192.

\section{REFERENCES}

[ANSI/ASHRAE Standard 55-2010] ANSI/ASHRAE Standard 552010: Thermal Environmental Conditions for Human Occupancy. Downloaded: 06/06/2021. Available online: http://arco-hvac.ir/wp-content/uploads/2015/11/ASHRAE-552010.pdf

[Causone 2009] Causone, F., et al. Experimental evaluation of heat transfer coefficients between radiant ceiling and room. Energy and Buildings, 2009, Vol. 41, pp. 622-628.

[Chiang 2012] Chiang, W-H., Wang, Ch-Y., Wang, J-S. Evaluation of cooling ceiling and mechanical ventilation systems on thermal comfort using CFD study in an office for subtropical region. Building and Environment, 2012, Vol. 48, pp. 113-127.

[Corny 2009] Corny, I., Straka, L., Mihalcova, J. Convection models and their application in simulation programs in environmental engineering (Konvekcné modely a ich aplikacia v simulacných programoch $v$ technike prostredia). Strojarstvo extra, 2009, No. 5, pp. 6/1-6/4. (in Slovak)

[Corny 2013] Corny, I. and Fedak, M. Equation model of thermal comfort parameters. In: Proc. of 13th Int. Sci. Conf. "Energetické premeny v priemysle". High Tatras, Slovakia, Sept. 25-27, 2013. Kosice: TUKE, 2013 pp. 25-27.

[Diaz 2010] Diaz, N.F, Lebrun, J., Andre, P. Experimental study and modeling of cooling ceiling systems using steady-state analysis. International journal of refrigeration, 2010, Vol. 33, pp. 793-805.

[Driss 2016] Driss, S., et al. Computational study and experimental validation of the heat ventilation in a living room 
with a solar patio system. Energy and Buildings, 2016, Vol. 119, pp. 28-40.

[Imanari 1999] Imanari, T., et al., Thermal comfort and energy consumption of the radiant ceiling panel system. Comparison with the conventional all-air system, Energy and Buildings, 1999, Vol. 30, pp. 167-175.

[Jeong 2003] Jeong, J.-W., Mumma, S.A. Ceiling radiant cooling panel capacity enhanced bymixed convection in mechanically ventilated spaces. Appl. Therm. Eng., 2003, Vol. 23, No. 18, pp. 2293-2306.

[Kalliomaki 2016] Kalliomaki, P., Saarinen, P., Wei-Tze Tang, J., Koskela, H. Airflow patterns through single hinged and sliding doors in hospital isolation rooms - Effect of ventilation, flow differential and passage. Building and Environment, 2016, Vol. 107, pp. 154-168.

[Lenhard 2019] Lenhard, R., Malcho, M., Jandacka, J. Modelling of heat transfer in the evaporator and condenser of the working fluid in the heat pipe. Heat transfer engineering, 2019, Vol. 40, No. 3-4, pp. 215-226.

[Micallef 2016] Micallef, D. Cross-ventilation of a room in a courtyard building. Energy and Buildings, 2016, Vol. 133, pp. 658-669.

[Murcinkova 2013] Murcinkova, Z., Krenicky, T. Implementation of virtual instrumentation for multiparametric technical system monitoring. In: SGEM 2013: 13th Int. Multidisciplinary Sci. Geoconf. Vol. 1: 16-22 June, 2013, Albena, Bulgaria. Sofia: STEF92 Technology, 2013. pp. 139-144. ISBN 978-954-91818-9-0.

[Nahornyi 2018] Nahornyi, V., Panda, A. Prediction methodology of technogenic and natural events and phenomena. Production Engineering, 2018, pp. 96-103.

[Olesen 2000] Olesen, B.W., et al. Heat exchange coefficient between floor surface and space by floor cooling - theory or a question of definition. In: ASHRAE Transactions 2000; Dallas, TX (US), 02/05/-02/09/2000; 2000, Vol. 106, Part 1, pp. 684-694.

[Rimar 2018] Rimar, M., et al., Study of gaseous flows in closed area with forced ventilation. MM Science Journal, 2018, Vol. March, pp. 2188-2191.

[Su 2019] Su, X., et al. A computational model of an improved cooling radiant ceiling panel system for optimization and design. Building and Environment, 2019, Vol. 163, No. 106312, pp. 1-11.

[Tian 2012] Tian, Z., et al. Research on the actual cooling performance of ceiling radiant panel. Energy and Buildings, 2012, Vol. 47, pp. 636-642.

[Vahovsky 2019] Vahovsky, J., et al. Case Study of Smart-based Cooling System Application. Advances in Thermal Processes and Energy Transformation, 2019, Vol. 2, No. 1, pp. 15-18.

[Xie 2016] Xie, D., et al. Numerical analysis of temperature nonuniformity and cooling capacity for capillary ceiling radiant cooling panel. Renewable Energy, 2016, Vol. 87, pp. 1154-1161.

\section{CONTACTS:}

Prof. Ing. Miroslav Rimar, CSc.

Assoc. Prof. Ing. Marcel Fedak, PhD.

Ing. Andrii Kulikov, PhD.

Ing. Olha Kulikova, PhD.

Technical University of Kosice

Faculty of Manufacturing Technologies with a seat in Presov

Department of Process Technique

Sturova 31, 08001 Presov, Slovak Republic

tel.: +421-55-602-6341

e-mail: miroslav.rimar@tuke.sk; marcel.fedak@tuke.sk; andrii.kulikov@tuke.sk; olha.kulikova@tuke.sk 